\title{
Effects of Dual Task Exercises Training Program on Stroke Patients
}

\section{Asmaa Mohammed Mohammed ${ }^{1}$, Amira Ahmed Hassanein ${ }^{2}$, Hanan Gaber Mohammed Mahmoud $^{3}$, Mohammad Kamal Hamed Senna ${ }^{4}$ and Eman Sobhy Omran ${ }^{5}$}

(1) Instructor at Technical Institute of Nursing, (2) Professor of Medical Surgical Nursing, Faculty of Nursing, Mansoura university, (3) professor of Medical Surgical Nursing, Faculty of Nursing, Benha University, (4) Professor of Physical Medicine, Rehabilitation and Rheunstology, Faculty of medicine, Mansoura University, (5)Lecturer of Medical Surgical Nursing, Faculty of Nursing, Benha University.

\section{Abstract}

Background: Stroke is a neurologic disorder considered the first cause of disability among adults worldwide. The most important goal of treatment in stroke patients is to return the patients to society. Dual tasks have clinical significance in a number of areas in enhancement of the balance and mobility of patients. The aim of the current study was to evaluate the effects of dual task exercises training program on balance, mobility and risk of falling in stroke patients and its impact on Activities of Daily Living (ADL). Research design: A quasi-experimental research design was utilized to conduct this study. Setting: This study was conducted at Neurological Department of Benha University Hospital. Sample: A purposive sample of 104 adult stroke patients who divided into intervention and control groups equally. Tools of data collection: Five tools were used for data collection. I: Structured neurological assessment sheet, II: Postural assessment scale for stroke, III: Timed up and go test, VI: Barthel index scale of ADL and V: Activities-specific balance confidence scale. Results: Hypertension is the most common risk factor among both groups, post intervention, BI (ADL dependency) of intervention group is significantly associated with their PASS score (level of balance) Conclusion: Dual task exercises training program was effective in improving clinical outcomes in patients with stroke. Recommendations: Nurses should be encouraged to implement the dual task exercises training as a routine practice for stroke patients to improve balance, mobility, risk of falling and ADL.

Keywords: Dual Task Exercises, Stroke, Training Program.

\section{Introduction}

The World Health Organization (WHO) defined stroke as "rapid development of clinical symptoms of global or focal disruption of cerebral functioning, that persisting twenty four hours or more or causing death, without any obvious origin except of vascular causes (Donkor, 2018). A stroke is also known as a cerebrovascular accident or a brain attack which is a global health problem. It is the brain equivalent of a heart attack. Blood must flow to and through the brain to function; stroke occurs if the continuous supply of blood to an area of the brain is interrupted by a blood coagulate or by narrowing or bursting of blood vessels. Consequently, brain cells are deprived of oxygen and begin to die after a few minutes, and that results in brain damage (Van de Steene, 2019).

Stroke is the second most common morbidity cause worldwide, after myocardial infarction. Annually, around 15 million 


\section{$\underline{\text { Effects of Dual Task Exercises Training Program on Stroke Patients }}$}

individuals worldwide suffer a stroke. About a quarter of strokes happen in people aged less than 65 years. Recurrent stroke is common in stroke survivors and around a quarter of people who recover from their first stroke will have another one within 5 years (Vos et al., 2016). Stroke remains a leading cause of long-term disability, it is the third cause of death and the first cause of acquired adult disability in the world, making the improvement of post stroke outcomes a major healthcare objective (Benjamin et al., 2017).

There are a wide range of post stroke problems that affect mobility, balance, cognition, attention, memory, sensation, perception and emotion (Yoon-Hee, Kyoung, Sang-Yong \& Yong-Jun, 2020). The physical and psychosocial consequences of stroke are complex and long term. Longer-term problems are reported by stroke survivors 1 to 5 years post stroke, the most common include mobility $58 \%$, fatigue $52 \%$, concentration $45 \%$ and falls $44 \%$. About half of those surviving describe that their needs regarding these problems are not being met and this is more common among those who are more disabled (Saunders, Greig \& Mead, 2014).

Motor impairment is the most common and widely recognized impairment caused by stroke. It usually affects the control of movement of the face, arm and leg on one side of the body and is seen in about $80 \%$ of stroke patients. More than $30 \%$ of survivors still cannot walk independently. Therefore, stroke rehabilitation should be focused on recovery of physical independence and functional ability during ADL to improve the function of walking and improve balance and mobility (Pollock et al., 2014).

Dual-tasking training requires subjects to simultaneously perform complex tasks, for example motor and cognitive tasks, allowing them to improve their coordination of various tasks (Takeuchi et al., 2020). Cognitive-motor tasks are important for various ADL, such as walking while holding a conversation. Additionally, dual tasks can be two motor tasks to allow for different motor processes to occur simultaneously to further stimulate the damaged brain (Liu et al. 2018).

Stroke patients often have great difficulty with performing dual-tasks while standing or walking and reduced dual-tasking ability has significant effects on patients' mobility, safety, and daily functioning, also increase fall hazard (Rai \& Ganvir, 2020).

\section{Significance of the study:}

The epidemiology of stroke is changing rapidly and the global stroke burden continues to increase worldwide. Today stroke is a major health problem in the Egyptian population (EIHajj, Salameh, Rachidi \& Hosseini, 2016); furthermore, Egypt is the most populous nation in the Middle East and the incidence and prevalence of stroke in Egypt are high weighted by $613 / 100,000$ and 202/100,000 respectively (Abd-Allah, Khedr, Oraby, \& Reda, 2019).

Performing dual-tasks is essential to daily life. During everyday tasks, for example crossing a street, we concurrently need to monitor the environment for upcoming cars or cyclists, and sometimes also talk with someone else, or increasingly so busy ourselves with our smartphone. For various healthy people, walking is mostly automated such that dual-task execution can normally be done without harm or much effort (Kal, 2018). In fact, although most stroke patients regain some degree of walking ability, their capacity for dual tasking does not substantially improve (Rai \& Ganvir, 2020). This can be prevented through dual task exercises training to improve balance, mobility and risk of falling. 


\section{Aim of the study:}

This study aimed to evaluate the effects of dual task exercises training program on balance, mobility and risk of falling among stroke patients and its impact on ADL.

\section{Research hypothesis:}

Stroke patients who would perform dual task exercises training would exhibit improvement in their balance, mobility, reduced risk of falling, and independent activities of daily living in comparison to those who will receive routine nursing care only.

\section{Subjects and Method}

Study design: Quasi-experimental research design was utilized to conduct this study.

Setting: This study was conducted at Neurological Department of Benha University Hospital.

\section{Subjects:}

A purposive sample composed of 104 stroke patients of both genders were assigned from Department of Neurology and randomized into two equal groups (control and intervention group including 52 patients in each group), the two groups received range of motion exercises and routine nursing care during their period of hospitalization. Additional 8 sessions of dual task exercise training were provided to the intervention group only.

\section{Tools of data collection:}

The following five tools were used for data collection:

\section{Tool (I): Structured Neurological Assessment.}

This tool was developed by the researcher after passing through an extensive, relevant and recent review of literature, aimed to assess the patient's demographic data and clinical health status at the time of admission to neurological department.

\section{Tool (II): Postural Assessment Scale for} Stroke (PASS):

It was a reliable tool to measure and evaluate post-stroke balance and throughout the rehabilitation program. Good measurements of balance may predict later disability and risk of falling, assist in selecting the most appropriate therapy, and assess patients' changes. The PASS was developed by (Benaim, Perennou, Villy, Rousseaux \& Pelissier, 1999), and used by the researcher for patients in both groups pre and post the program. Its total score is 36

- Score is lower than $50 \%$ of total score (36): indicate a low level of balance

- Score is 50-65\%: indicate a moderate level of balance

- Score is > 65\%: indicate a high level of balance

\section{Tool (III): Timed Up and Go Test (TUGT):}

The Timed Up and Go test is a simple test used to assess mobility and identify the individuals with fall risk. TUGT was adopted from Podsiadlo \& Richardson, (1991). It measures the time that a person takes to stand from a chair, walk 3 meters, turn, walk back to the chair, and sit down. Time taken to make this sequence of actions was counted and recorded in seconds using a stopwatch.

\section{Scoring of TUGT:}

- 10 seconds or less: is normal.

- 11 to 19 seconds: indicates that the patient is at low risk for falling.

- 20 to 29 seconds: indicates that the patient is at moderate risk for falling.

- 30 seconds or more: indicates that the patient is at high risk of falling.

Tool (VI): Barthel Index (BI) Scale of Activities of Daily Living:

The ADL was measured using the Barthel index (BI). This scale was was adopted from (Collin, Wade, Davies \& Horne, 1988). It is an ordinal scale that was used to 
assess the patient level of ADL dependency. The BI composed of 10 items describing ADL to measure the degree of help needed by an individual on each of the ten items of ADL.

\section{Scoring of BI:}

Each item is rated based on observation $(0=$ unable, $1=$ needs help or $2=$ independent $)$. The final score is 20 and $x 5$ to get a number on a 100 point score.

- Score of 0-20: "total" dependency,

- 21-60: "severe" dependency,

- 61-90: "moderate" dependency,

- And 91-99: "slight" dependency.

\section{Tool (V): Activities-specific Balance}

Confidence (ABC) scale:

ABC scale was adopted from (Powell \& Myers, 1995). The ABC Scale is a self-report measure of balance confidence in performance of several activities without losing balance or feeling unsteady. It includes 16 tasks related to indoor and outdoor daily living activities, such as walking around the house, walking up and down stairs. Each task scored from 0\% (not confident at all) to $100 \%$ (completely confident). Total score ranges from 0 to 1600 and divided by 16 (number of items) to get the patient's overall percentage of balance confidence.

\section{Scoring of ABC scale:}

- $80 \%=$ high level of physical functioning

- $50-80 \%=$ moderate level of physical functioning

- $<50 \%=$ low level of physical functioning

\section{Dual task exercises training program:}

The program aimed to improve balance, mobility, reduce risk of falling, and promote independent activities of daily living and selfconfidence. It was developed by the researcher after passing through an extensive and relevant review of literature (Brown et al., 2016; Chuang et al., 2017; Liu, Yang, Tsai \& Wang, 2017; Uzunkulaoğlu, Kerim, Ay \& Ergin, 2019; Wollesen, Schulz, Seydell \& Delbaere, 2017) and others. The program was summarized and translated into simple arabic words supported by clear and descriptive pictures in the form of simple instructional booklet.

\section{Dual task exercises were categorized in the following challenge levels:}

1) Range of Motion Exercises (ROM) to preserve flexibility and mobility of the joints and muscles, and prevent any stiffness in a joint or tightness in muscle.

2) Single-task balance training exercises: This level began with simple and basic balance exercises for example (dynamic weight shifting, sit to stand exercise, and heel raise while sitting on a chair), during these exercises; the patients were allowed to hold onto something to maintain their balance and ensure they wouldn't fall. After that the researcher increased difficulty by encouraging the patients to perform these exercises but without holding onto something.

3) Cognitive-motor dual-task balance training exercises: In these exercises the patients were exposed to a variety of cognitive tasks while performing motor exercises with increased difficulty, this is designed to challenge their focus of attention for example (sitting and recite numbers, days, or months backward, walking while telling story, and tell opposite direction of action).

4) Motor-motor dual-task balance training exercises: in these exercises, motor tasks were also included as added tasks for example (standing while throwing and catching a ball, walk and kick a ball, and walking while holding a cup of water without spilling it)

5) Imitated activities of daily living: the program was completed by a range of activities 
designed to simulate common daily situations such as (sit to stand and walk, sit to stand and pick up objects from the floor, and walk toward/beside/behind a person moving at a consistent speed and direction).

\section{Ethical consideration:}

Ethical approval was obtained from research ethics committee at the Faculty of Nursing Benha University. A written official approval for conducting the study was obtained from the directors of Benha University Hospital. Each patient was informed about the purpose, nature and significance of the study, the participants were assured that confidentiality of the collected data will be maintained and the results will be used for research purposes as well as for future publication and education only.

\section{Validity of tools:}

After developing tool (1), it was tested by a jury of 5 experts in the field of the study, two experts of Medical Surgical Nursing at Mansoura University, one expert of Medical Surgical Nursing at Benha University and two experts of Physical Medicine, Rehabilitation and Rheunstology at Faculty of Medicine Mansoura University, to measure its internal validity and determine that the tools and program covered the aim of the study. All necessary modifications were carried out accordingly.

Reliability of tool I: was tested for its internal consistency using Cronbach's Alpha test, the coefficient value was 0.839 .

\section{A pilot study:}

Used to assess the clarity and applicability of data collection tools, was carried out on $10 \%$ of study sample (11 patients), those patients were not included in the actual study, and necessary modifications were carried out.

\section{Data collection:}

- Once the necessary approval granted to proceed with the proposed study, stroke patients who met sampling criteria and accepted to participate in the study were individually interviewed.

Before assessment and intervention, the researcher introduced herself to the patients, explained the aim of the study and took the oral consent from patients and their next of kin and the researcher emphasized the importance of active participation and follow up, simultaneously. The patient right to withdraw at any time without any embarrassment or effect on patient care, they take part in the study on a voluntary basis.

- Data collection was classified into three phases:

\section{Assessment phase:}

This phase began once the participants became at least active assistive, during this phase the researcher collected data from both groups before implementing dual task exercises training program to obtain baseline data using the prepared study tools

\section{Implementation phase:}

- Based on the patients' assessment, the program was planned and started for the patients in the intervention group only; patients in intervention group completed 8 sessions of dual-task balance training exercises for one month, twice a week, with total duration of training each session lasted for an average of $30 \mathrm{~m}$, each participant received individualized (one participant) training sessions, during each session the researcher used simple, clear and easy language to be understood by the patients.

- Each participated patient was provided with a booklet consisting of exercises to be 


\section{$\underline{\text { Effects of Dual Task Exercises Training Program on Stroke Patients }}$}

followed at home with instructions and pictorial illustrations to attract their attention and to be as a reference to review and remember instructions while performing exercises at home.

- At the end of each session, a brief summary emphasized on the important points was given to the patients and they were encouraged to ask questions, each patient is given his or her next appointment date.

- Regarding Control Group: The patients received the routine nursing care only and carry on with their usual activities.

\section{Evaluation phase:}

After completion of the one-month training program, the researcher evaluated the effect of dual task exercises training program and routine nursing care on intervention group regarding their balance, mobility, risk of falling and self-confidence using (Tool II, III, IV and V) immediately at the end of program (post) within one month following the last session.

A follow up assessment one month later was also conducted. During this period (between post and follow up assessment), the patient adherence to home exercise is ensured either by direct, routine follow up at hospital every 15 days or telephonically. Patients were instructed to come for follow-up at any time during this period when they forget or need to have any other problem while performing it.

\section{Statistical analysis:}

All statistical analyses were performed using SPSS for windows version 21.0 (SPSS, Chicago, IL). Data were tested for normality of distribution prior to any calculations and were of normal distribution. Continuous data were expressed in mean \pm standard deviation while categorical data were expressed in number and percentage. The comparisons were determined using Student's t test for variables with continuous data. Chi- square test was used for comparison between variables with categorical data. The linear regression analysis was played to explore the association of PASS score, ABC score and TUG score with the Berthel index post intervention and at follow up. Statistical significance was set at $\mathrm{p}<0.05$.

\section{Results}

Table (1) shows that, a total of (104) patients were enrolled in the current study with their mean age was $(54.1 \pm 6.0$ and $54.3 \pm 5.6)$ in the intervention and control groups respectively. $71.2 \%$ vs. $75.0 \%$ of the intervention and control groups respectively were ranged between 50 to 60 years. Regarding gender, $55.8 \%$ vs. $57.7 \%$ of the intervention and control groups consecutively were females. According to level of education, $51.9 \%$ vs. $50.0 \%$ of the intervention and control groups consecutively were illiterate. Concerning marital status, $96.2 \%$ vs. $92.3 \%$ of both intervention and control groups respectively were married. As regards to living condition, $94.2 \%$ vs. $96.2 \%$ of intervention and control groups consecutively were living with family. In reference to smoking habits, $78.8 \%$ and $75.0 \%$ of the intervention and control groups consecutively were nonsmokers. No significant difference was detected between the two groups, where ( $p$ value $>0.05)$.

Table (2) shows that, $90.4 \%$ of the studied groups had chronic diseases which caused stroke development, it was noticed that, hypertension is the most common risk factor among both groups which distributed as $78.8 \%$ in the intervention group and $75.0 \%$ of the control group, followed by diabetes mellitus which distributed as $44.2 \%$ in both groups, while few of patients in the intervention and control group had cardiac disease $21.2 \%$ and $19.2 \%$ respectively. it's also noted that, the majority of the subjects in intervention and 
control groups had no family history of stroke, respectively, (90.4\% \& 94.2\%). No significant difference was detected between the two groups, where (p-value >0.05).

Figure (1) illustrates that, mean PASS score for the intervention and control groups were, consecutively, $(10.3 \pm 2.8$ vs. $11.0 \pm 3.7)$ preintervention and improved to $(16.5 \pm 2.8$ vs. $16.8 \pm 3.9$ ) post-intervention with no statistically significant difference neither pre nor post intervention $(\mathrm{P}>0.05)$. But at follow up, mean score improved to $(28.4 \pm 5.1$ vs. 24.8 \pm 4.9) for intervention and control groups consecutively with highly statistical significant difference in favor of the intervention group $(\mathrm{P}<0.001)$.

Table (3) illustrates that the majority of studied patients $(96.2 \%$ and $90.4 \%)$ of intervention and control groups respectively, have the same low level of balance on pre-intervention assessment with no significant difference. At post intervention assessment, this percentage decreased to $(61.5 \%$ vs. $57.7 \%)$ but there was no statistical difference $(\mathrm{P}>0.05)$. while at follow up, the majority of intervention group $(84.6 \%)$ and more than half $(59.6 \%)$ of the control group improved to high level of balance with a significant difference between both groups $(\mathrm{P}=0.006)$.

Figure (2) portrays mean scores of BI of ADL for two study groups and shows that, no significant difference was detected in preintervention assessment, where ( $\mathrm{P}>0.05)$. Whereas in post-intervention and follow up assessment, the statistically significant difference was noticed, where $(p=0.005 \&$ 0.002), respectively.

Table (4) reveals that, nearly three quarters $(75.0 \%$ vs. $76.9 \%)$ of intervention and control groups respectively were at high risk for falling on pre-intervention assessment with no statistically significant difference between the two groups. While on post-intervention assessment, these percentages decreased to less than half $(48.1 \%)$ of intervention group compared to more than half $(55.8 \%)$ of control group were at high risk for falling, and at follow up assessment less than half (40.4\% vs. $46.2 \%)$, respectively of intervention and control groups were at moderate risk for falling. Statistically significant difference was found between groups on post-intervention and at follow up assessment, where $(\mathrm{P}=0.012 \quad \& \quad 0.009)$ consecutively.

Table (5) clarifies that, according to $\mathrm{ABC}$ scale total score grading, all participants $(100 \%)$ in both intervention and control groups were at low level of physical functioning as a baseline assessment, this percent decreased to $(92.3 \%$ and $94.2 \%$ ) in intervention and control groups, respectively post intervention, with no significant difference pre and post intervention. while at follow up, this percent decreased to $(80.8 \%$ and $94.2 \%)$ in the intervention and control groups respectively, with statistically significant difference, where $(\mathrm{p}=0.038)$.

In table (6), the linear regression analysis model showed that, post intervention, BI (ADL dependency) of intervention group is significantly associated with their PASS score (level of balance), ABC score (self-confidence), and TUG score (risk for falling), where $(p=0.046,0.003 \& 0.015)$ respectively.

In table (7), the linear regression analysis model showed that, at follow up, BI (ADL dependency) of intervention group is significantly associated with their PASS score (level of balance), ABC score (self-confidence), and TUG score (risk for falling), where ( $p=0.048,0.004 \& 0.038)$ respectively. 
$\underline{\text { Effects of Dual Task Exercises Training Program on Stroke Patients }}$

Table 1. Frequency Distribution and Significant Difference between Studied Groups Regarding their Demographic Data and Life Style:

\begin{tabular}{|c|c|c|c|c|c|c|}
\hline \multirow[t]{2}{*}{ Variables } & \multicolumn{2}{|c|}{$\begin{array}{l}\text { Intervention } \\
\text { Group }\end{array}$} & \multicolumn{2}{|c|}{$\begin{array}{l}\text { Control } \\
\text { Group }\end{array}$} & \multicolumn{2}{|c|}{ Chi square test } \\
\hline & n (52) & $\%$ & n (52) & $\%$ & $\mathbf{X}^{2}$ & $\mathbf{P}$ \\
\hline \multicolumn{7}{|l|}{ Age (years) } \\
\hline $30-$ & 2 & 3.8 & 2 & 3.8 & & \\
\hline $40-$ & 13 & 25.0 & 11 & 21.2 & & \\
\hline $50-60$ & 37 & 71.2 & 39 & 75.0 & 0.219 & 0.896 \\
\hline Mean \pm SD & \multicolumn{2}{|c|}{$54.1 \pm 6.0$} & \multicolumn{2}{|c|}{$54.3 \pm 5.6$} & 0.153 & 0.879 \\
\hline \multicolumn{7}{|l|}{ Gender } \\
\hline Male & 23 & 44.2 & 22 & 42.3 & & \\
\hline Female & 29 & 55.8 & 30 & 57.7 & 0.039 & 0.843 \\
\hline \multicolumn{7}{|c|}{ Educational level } \\
\hline Illiterate & 27 & 51.9 & 26 & 50.0 & & \\
\hline Read/write & 7 & 13.5 & 10 & 19.2 & & \\
\hline Basic & 4 & 7.7 & 3 & 5.8 & & \\
\hline Secondary & 9 & 17.3 & 10 & 19.2 & & \\
\hline Higher & 5 & 9.6 & 3 & 5.8 & 1.244 & 0.871 \\
\hline \multicolumn{7}{|l|}{ Marital status } \\
\hline Unmarried & 2 & 3.8 & 4 & 7.7 & & \\
\hline Married & 50 & 96.2 & 48 & 92.3 & 0.707 & 0.400 \\
\hline \multicolumn{7}{|c|}{ Living condition } \\
\hline live alone & 3 & 5.8 & 2 & 3.8 & & \\
\hline With family & 49 & 94.2 & 50 & 96.2 & 0.210 & 0.647 \\
\hline \multicolumn{7}{|l|}{ Smoking habits } \\
\hline Non-smoker & 41 & 78.8 & 39 & 75.0 & & \\
\hline Smoker & 11 & 21.2 & 13 & 25.0 & 0.217 & 0.642 \\
\hline
\end{tabular}

Table 2. Frequency Distribution and Significant Difference between Studied Groups Regarding their Risk Factors for Stroke:

\begin{tabular}{|c|c|c|c|c|c|c|}
\hline \multirow[t]{2}{*}{ Variables } & \multicolumn{2}{|c|}{$\begin{array}{l}\text { Intervention } \\
\text { Group }\end{array}$} & \multicolumn{2}{|c|}{$\begin{array}{l}\text { Control } \\
\text { Group }\end{array}$} & \multicolumn{2}{|c|}{ Chi square test } \\
\hline & $\begin{array}{c}n \\
(52)\end{array}$ & $\%$ & $\begin{array}{c}\mathbf{n} \\
(\mathbf{5 2})\end{array}$ & $\%$ & $\mathbf{X}^{2}$ & $\mathbf{P}$ \\
\hline Hypertension & 41 & 78.8 & 39 & 75.0 & 0.217 & 0.642 \\
\hline Diabetes mellitus & 23 & 44.2 & 23 & 44.2 & 0 & 1.000 \\
\hline Cardiac disease & 11 & 21.2 & 10 & 19.2 & 0.060 & 0.807 \\
\hline Family history of stroke & 5 & 9.6 & 3 & 5.8 & 0.542 & 0.462 \\
\hline
\end{tabular}




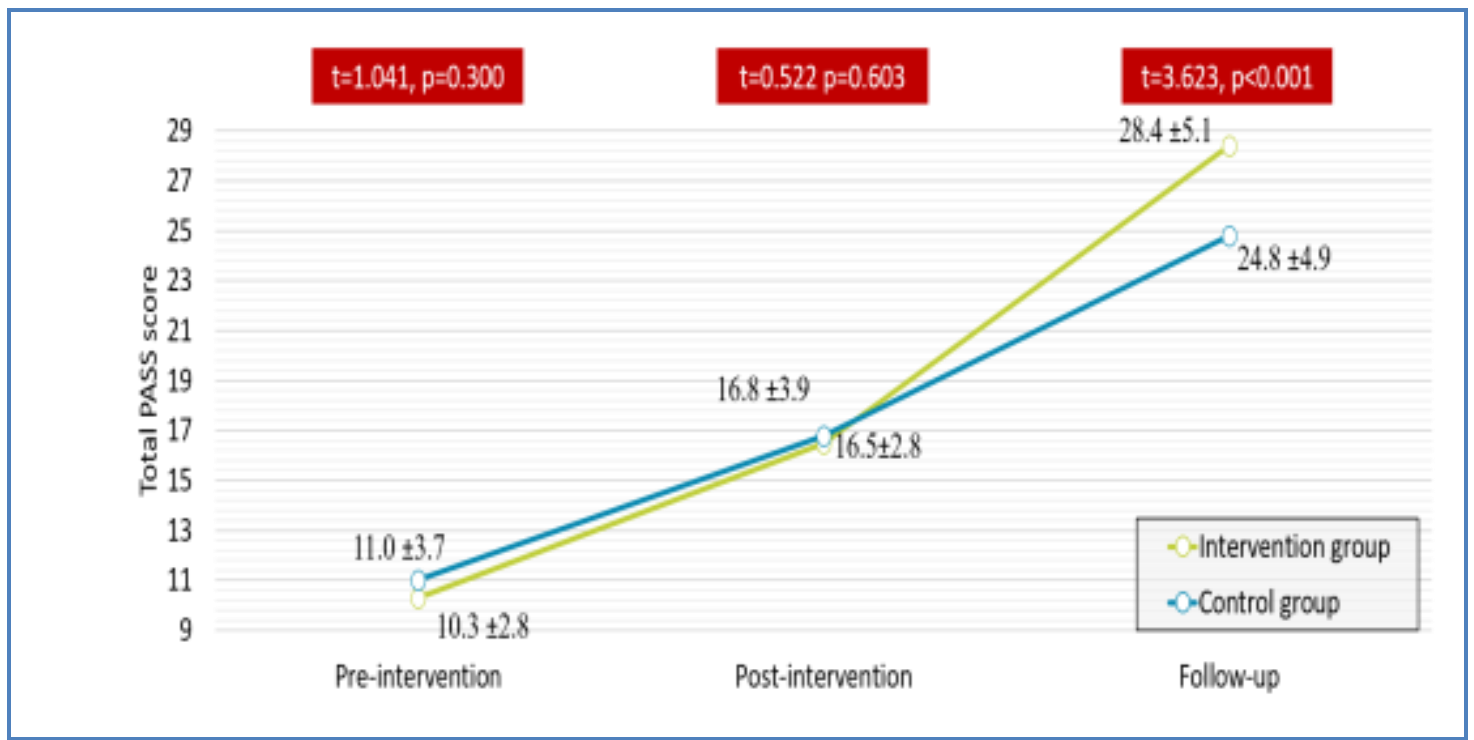

Figure (1 )Mean \pm SD and Significant Difference between Studied Groups according to their

Postural Assessment Scale Score Pre and Post-intervention and at Follow-up $n=(52$ intervention \& 52 control)

Table (3) Frequency Distribution and Significant Difference between Studied Groups regarding their Level of Balance Using Postural Assessment Scale Pre and Post-intervention and at Follow up:

\begin{tabular}{|c|c|c|c|c|c|c|}
\hline \multirow[t]{2}{*}{ Variables } & \multicolumn{2}{|c|}{$\begin{array}{l}\text { Intervention } \\
\text { Group }\end{array}$} & \multicolumn{2}{|c|}{$\begin{array}{l}\text { Control } \\
\text { Group }\end{array}$} & \multicolumn{2}{|c|}{ Chi square test } \\
\hline & n (52) & $\%$ & n (52) & $\%$ & $\mathbf{X}^{2}$ & p \\
\hline \multicolumn{7}{|l|}{$\begin{array}{l}\text { PASS grades pre } \\
\text { intervention }\end{array}$} \\
\hline Low level of balance & 50 & 96.2 & 47 & 90.4 & & \\
\hline $\begin{array}{l}\text { Moderate level of balance } \\
\text { PASS grades post } \\
\text { intervention }\end{array}$ & 2 & 3.8 & 5 & 9.6 & 1.378 & 0.240 \\
\hline Low level of balance & 32 & 61.5 & 30 & 57.7 & & \\
\hline Moderate level of balance & 20 & 38.5 & 19 & 36.5 & & \\
\hline High level of balance & 0 & 0.0 & 3 & 5.8 & 3.090 & 0.213 \\
\hline PASS grades at follow up & & & & & & \\
\hline Low level of balance & 0 & 0.0 & 6 & 11.5 & & \\
\hline Moderate level of balance & 8 & 15.4 & 15 & 28.8 & & \\
\hline High level of balance & 44 & 84.6 & 31 & 59.6 & 10.384 & $0.006^{*}$ \\
\hline
\end{tabular}

(*) Statistically significant at $P \leq 0.05$

PASS scoring system:

- Scores lower than $50 \%$ of total score (36): indicate a low level of balance

- Scores 50-65\%: indicate a moderate level of balance

- Scores $>65 \%$ : indicate a high level of balance 
$\underline{\text { Effects of Dual Task Exercises Training Program on Stroke Patients }}$

Table (4) Frequency Distribution and Significant Difference between Studied Groups regarding their Risk for Falling Using Timed Up and Go (TUG) Test Risk for Falling Pre and Post-intervention and at Follow up:

\begin{tabular}{|c|c|c|c|c|c|c|c|c|c|c|c|c|c|c|}
\hline \multirow{3}{*}{$\begin{array}{r}\text { Timed Up and Go } \\
\text { (TUG) Test }\end{array}$} & \multicolumn{6}{|c|}{$\begin{array}{c}\text { Intervention } \\
\text { Group }\end{array}$} & \multicolumn{6}{|c|}{$\begin{array}{c}\text { Control } \\
\text { Group }\end{array}$} & \multirow{2}{*}{\multicolumn{2}{|c|}{ Chi square }} \\
\hline & \multirow{2}{*}{$\begin{array}{r}\text { Low } \\
\text { N }\end{array}$} & $\begin{array}{r}\text { risk for } \\
\text { falling }\end{array}$ & \multicolumn{2}{|c|}{$\begin{array}{r}\begin{array}{r}\text { Moderate risk } \\
\text { for falling }\end{array} \\
\end{array}$} & \multicolumn{2}{|c|}{$\begin{array}{cc}\text { High risk of } \\
\text { falling }\end{array}$} & \multicolumn{2}{|c|}{$\begin{array}{rr}\text { Low risk for } \\
\\
\text { falling }\end{array}$} & \multicolumn{2}{|c|}{$\begin{array}{r}\text { Moderate risk } \\
\text { for falling }\end{array}$} & \multicolumn{2}{|c|}{$\begin{array}{rr}\text { High } & \text { risk of } \\
& \text { falling }\end{array}$} & & \\
\hline & & $\%$ & $\mathbf{N}$ & $\%$ & $\mathbf{N}$ & $\%$ & $\mathbf{n}$ & $\%$ & $\mathbf{N}$ & $\%$ & $\mathbf{n}$ & $\%$ & $\mathbf{X} 2$ & $\mathbf{p}$ \\
\hline Pre-intervention & 2 & 3.8 & 11 & 21.2 & 39 & 75.0 & 0 & 0.0 & 12 & 23.1 & 40 & 76.9 & 2.056 & 0.358 \\
\hline Post-intervention & 14 & 26.9 & 13 & 25.0 & 25 & 48.1 & 3 & 5.8 & 20 & 38.5 & 29 & 55.8 & 8.899 & $0.012^{*}$ \\
\hline Follow up & 21 & 40.4 & 21 & 40.4 & 10 & 19.2 & 8 & 15.4 & 24 & 46.2 & 20 & 38.5 & 9.361 & $0.009 *$ \\
\hline
\end{tabular}

(*) Statistically significant at $\mathbf{P} \leq \mathbf{0 . 0 5}$

\section{Interpretation:}

- 10 seconds or less: is normal.

- 11 to 19 seconds: indicates that the patient has good mobility and is at low risk for falling.

- 20 to 29 seconds: indicates that the patient has mobility problems and is at moderate risk for falling.

- 30 seconds or more: indicates that the patient has impaired mobility and is at high risk for falling. 
Asmaa Mohammed, Amira Ahmed, Hanan Gaber, Mohammad Kamal and Eman Sobhy

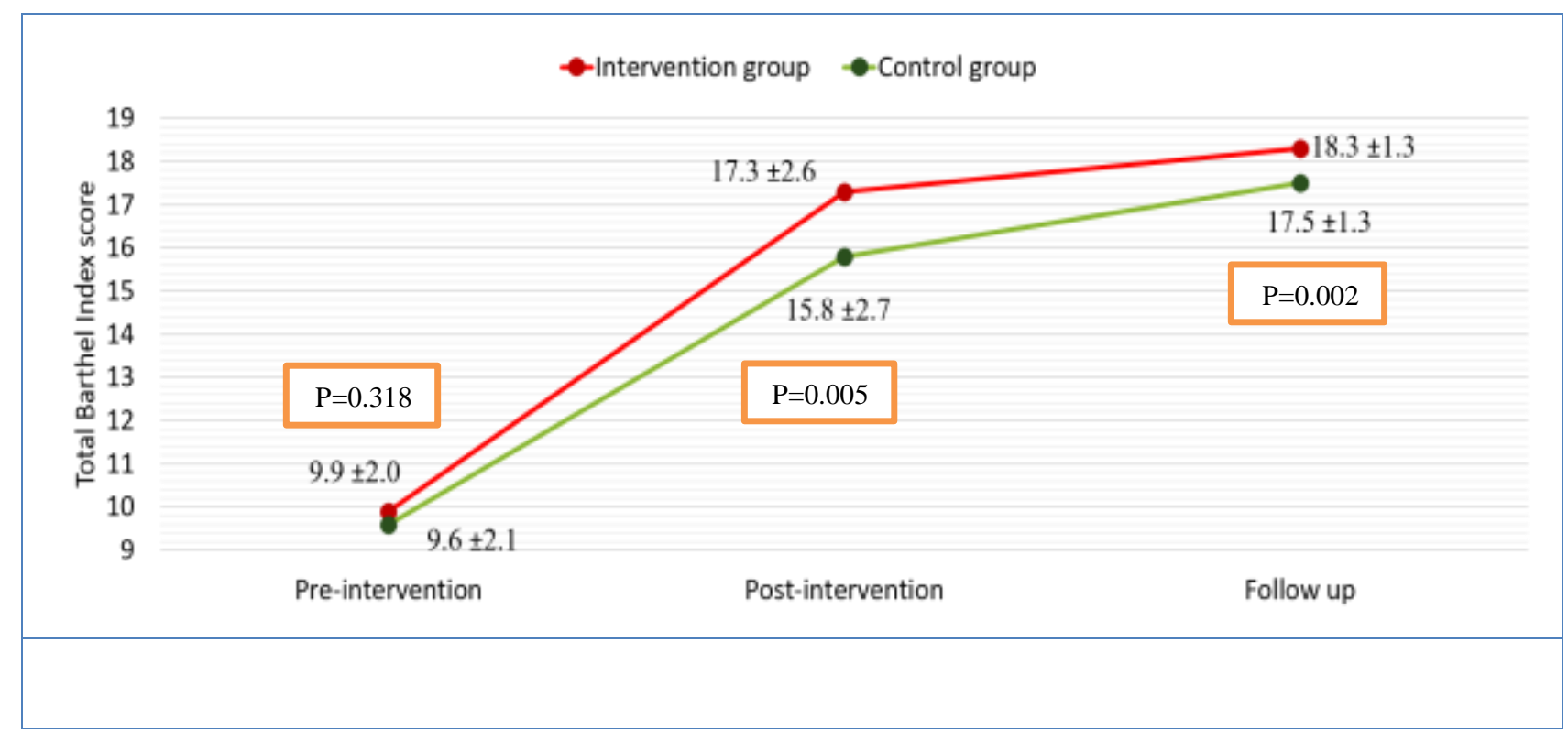

Figure (2) Mean \pm SD and Significant Difference between Studied Groups regarding their Barthel Index (BI) of Activities of Daily Living pre and post-intervention and at follow up $n=(52$ intervention \& 52 control $)$

Table (5) Frequency Distribution and Significant Difference between Studied Groups regarding their Activities-specific Balance Confidence (ABC) total score Pre and Postintervention and at Follow up:

\begin{tabular}{|c|c|c|c|c|c|c|}
\hline \multirow[t]{2}{*}{ ABC Score } & \multicolumn{2}{|c|}{$\begin{array}{l}\text { Intervention } \\
\text { Group }\end{array}$} & \multicolumn{2}{|c|}{$\begin{array}{l}\text { Control } \\
\text { Group }\end{array}$} & \multicolumn{2}{|c|}{$\begin{array}{l}\text { Chi square } \\
\text { test }\end{array}$} \\
\hline & n (52) & $\%$ & $\begin{array}{l}\mathrm{n} \\
(\mathbf{5 2})\end{array}$ & $\%$ & $\chi^{2}$ & $\mathbf{P}$ \\
\hline \multicolumn{7}{|l|}{ Pre-intervention } \\
\hline Low level of physical functioning & 52 & 100.0 & 52 & 100.0 & 0 & 1.000 \\
\hline \multicolumn{7}{|l|}{ Post-intervention } \\
\hline Low level of physical functioning & 48 & 92.3 & 49 & 94.2 & & \\
\hline $\begin{array}{l}\text { Moderate level of physical functioning } \\
\text { at follow up }\end{array}$ & 4 & 7.7 & 3 & 5.8 & 0.153 & 0.696 \\
\hline Low level of physical functioning & 42 & 80.8 & 49 & 94.2 & & \\
\hline Moderate level of physical functioning & 10 & 19.2 & 3 & 5.8 & 4.308 & $0.038 *$ \\
\hline
\end{tabular}

(*) Statistically significant at $\mathbf{P} \leq \mathbf{0 . 0 5}$

Scoring system of ABC scale:

- $>80 \%=$ high level of physical functioning

- $50-80 \%=$ moderate level of physical functioning

- $\quad<50 \%=$ low level of physical functioning 
Effects of Dual Task Exercises Training Program on Stroke Patients

\begin{tabular}{|c|c|c|c|c|c|}
\hline \multirow{3}{*}{ Variables } & \multicolumn{5}{|c|}{ Berthel Index } \\
\hline & \multicolumn{2}{|c|}{$\begin{array}{l}\text { Unstandardized } \\
\text { Coefficients }\end{array}$} & \multirow{2}{*}{$\begin{array}{r}\text { Standardized } \\
\text { Coefficients } \\
\text { Beta }\end{array}$} & \multirow[t]{2}{*}{$\mathbf{t}$} & \multirow[t]{2}{*}{ Sig. } \\
\hline & B & Std. Error & & & \\
\hline (Constant) & 11.364 & 1.647 & & 6.901 & $<0.001$ \\
\hline PASS score & 0.165 & 0.081 & 0.289 & 2.044 & $0.046^{*}$ \\
\hline ABC score & 0.051 & 0.016 & 0.456 & 3.148 & $0.003^{*}$ \\
\hline TUG score & 0.075 & 0.030 & 0.323 & 2.520 & $0.015 *$ \\
\hline
\end{tabular}

Table (7) Linear Regression Analysis Test of the Intervention Group Variables Associated with Berthel Index (ADL Dependency) at Follow up:

\begin{tabular}{|l|c|c|c|c|c|}
\hline \multirow{2}{*}{ Variables } & \multicolumn{5}{|c|}{ Berthel Index } \\
\cline { 2 - 6 } & $\begin{array}{l}\text { Unstandardized } \\
\text { Coefficients }\end{array}$ & $\begin{array}{l}\text { Standardized } \\
\text { Coefficients }\end{array}$ & T & Sig. \\
\cline { 2 - 6 } & B & Std. Error & Beta & \\
\hline (Constant) & 11.871 & 1.465 & & 8.103 & $<0.001$ \\
ABC score & 0.155 & 0.077 & 0.272 & 2.027 & $0.048^{*}$ \\
TUG score & 0.052 & 0.016 & 0.458 & 3.171 & $0.004^{*}$ \\
\hline
\end{tabular}

(*) Statistically significant at $\mathbf{P} \leq \mathbf{0 . 0 5}$

\section{Discussion}

Stroke is considered as a significant cause of prolonged disability that negatively impacts 16.9 million people every year, it is a devastating health problem and one of the leading causes of morbidity and mortality in developed and developing countries. Improvements in motor function following a stroke occur as the result of spontaneous recovery, learning and practice due to reorganization of the brain (Zhao \& Willing, 2018).

Regarding PASS, it was found that, the majority of patients of intervention and control groups have the same low level of balance. After one month of dual task training program intervention, the finding of the study showed that, post-intervention, both groups improved in their balance, but with no 
significant difference between them. It is possible that more frequent training $(>2$ sessions per week) or a longer training duration ( $>4$ weeks) may be required to induce greater improvement in their balance control.

While at follow up this study found high group difference in favor of the intervention group as the majority of intervention group compared to slightly more than one half of the control group improved to high level of balance. The findings of this study are in same line with the previous studies that had reported similar changes in balance control under dual task exercise conditions for patients with stroke. Choi, Kim, Han and Kim (2015) suggested that dual-task training was as valuable as conventional balance training to improve balance and cognition in post-stroke patients in a sub-acute phase. Also, Kim, Chun, Kang and Kim (2015) reported that the experimental group showed significant difference between pre and post assessment in PASS compared to control groups.

Moreover, in more recent research, this finding is consistent with de Sousa et al., (2019) who found that training or exercises aiming to improve sit-to-stand performance have beneficial effects in people who are unable to stand up independently after stroke compared with usual care, no treatment or an alternative intervention. Similarly, De Luca (2020) reported that the experimental group showed a statistical improvement in their balance score that was maintained at follow up.

In this study, TUG test was used to assess mobility and identify risk for fall in both groups before and after intervention and one month later, the results showed that, nearly three quarters of intervention and control groups were at high risk for falling on pre-intervention assessment with no statistically significant difference between both groups.

In this regard, the findings confirm with what has been found in other studies which showes a similar results. Schinkel-Ivy, Inness and Mansfield (2016) emphasized that specific features of balance and gait have been closely linked in stroke survivors; higher falls risk has been demonstrated in sub-acute stroke circumstances. This finding is also confirmed by studies of $\mathrm{Xu}$ et al., (2018) who demonstrated that worse disability and function are associated with increased falls risk.

The results also demonstrated that both groups showed improvements in TUG test (decrease in the TUG time) and risk for falling on post-intervention assessment but the intervention group showed greater improvement than the control group. Moreover, the intervention group maintained this improvement at follow up assessment; with statistically significant difference was found between intervention and control groups on post-intervention and at follow up assessment.

This result is supported by Aydoğdu, Aydoğdu and İnal (2018) who showed significant improvements in outcome of mobility between pre and post-intervention in both groups. However, the difference was significant in favor of the dual-task group. Based on their findings, walking with dualtask training can be used in addition to conventional stroke rehabilitation aiming to improve balance and mobility. Another study conducted by Pang et al., (2018) concluded that the dual-task program reduced the risk of falls and injurious falls by $25 \%$ and $22 \%$, respectively, when compared with the control 
group. On the other hand, this finding is in contrast with Meester et al., (2019) who reported that both groups improved significantly on walking distances under normal and dual-task situations.

This study evaluated effect of dual task exercises on ADL as measured by the BI. Post intervention we found that slightly more than one fifth of intervention group compared to only 3 patients of control group were slightly dependent and the difference between groups was found to be statistically significant in favor of intervention group. Moreover, this improvement was maintained at follow up with slightly less than half of intervention group compared to slightly less than one fifth of control group were slightly dependent with statistically significant difference. In this regard, results in the current study are similar to that reported in previous study conducted by Park (2019) who reported that a statistically significant effect of the dual-task training were observed (the study about chronic stroke patients' upper limb function and capability of performing daily tasks).

This result is in contrast to previous study of kong and lee (2014) which identified that BI scale didn't show any significance improvement except 3 months of post intervention. This difference can be attributed to older age participants included in the previous study which was a negative predictor of functional dependence due to additional disability and comorbidities in older patients. The present result also differs from that reported by Aydoğdu et al., (2018) who explored that, although both groups had increased functional independence and decreased fear of falling after the treatment program, there was no significant difference between the intervention and control groups.
Also, the finding of the study clarified that, all participants in intervention and control groups were at low level of physical functioning (balance self-confidence) as a baseline assessment with no statistically significant difference. This result is supported by Schinkel-Ivy, Inness and Mansfield (2016) study which showed that balance confidence has been closely linked in stroke survivors. Low balance confidence has been demonstrated in sub-acute stroke circumstances and interventions to minimize the impact of low balance confidence have been suggested.

Also, it was found that, in postintervention assessment, there was more improvement in self-confidence of participants in intervention group than in control group but this improvement wasn't statistically significant, this improvement reached statistical significance at follow up assessment in favor of the intervention group, although this improvement was very slight whether post intervention or at follow up. This finding can be attributed to the short duration; another possible explanation of the study finding is that the majority of participants were severely dependent. Perhaps a longer training duration or more intensive program is required to provoke improvements in high-level functioning.

This is similar to the results of Cortés-Pérez, Nieto-Escamez and ObreroGaitán (2020) who found that the patients in intervention group showed a larger improvement for risk of falls and balance as well as a higher reduction of fear of falling. In contrast, the patient who did not receive any treatment did not show changes in balance or fear of falling. This result is in disagreement with Meester et al., (2019) who surprisingly found that balance confidence improved relatively more in the 
control group with a statistically significant difference in favor of the control group. This was unexpected but is possibly explained by the larger proportion of 'no' responders at baseline in the control group.

Also this study revealed that, ADL dependency in intervention group is significantly associated with level of balance, self-confidence, and risk for falling post intervention and follow up. This result is in line with Kim and Park (2014), whose results supported the link between ADL independency and balance and balance selfconfidence in stroke patients. Similarly landers, Oscar, Sasaoka and Vaughn (2016) concluded that, balance confidence was the best predictor of falling, followed by falling risk.

Finally the current study findings supported the study hypotheses and showed that, dual task exercises training was effective to improve balance, mobility, reduced risk of falling, and independent ADL in intervention group. This finding is similar to that reported by $\mathbf{Y u}$ and Jeon (2015) whose study results showed positive effects of dual-task training on gait performance and the ability to perform the ADL in patients with neurological deficits exhibit the need for dual-task training. In addition, Park (2019) confirmed that dual-task training could have a positive effect not only on the upper limb function of the patients, but also on the daily life performance ability, which is the end goal of rehabilitation.

\section{Conclusion}

Dual task exercises training program was effective to improve balance, mobility, reduced risk of falling as well as performing independent $\mathrm{ADL}$ in intervention group as indicated by improvement in Timed Up and Go test and Barthel Index post intervention and improvement in Postural Assessment Scale, Timed Up and Go test, Barthel Index and Self-Confidence at follow up.

\section{Recommendations}

1. Nurses should be encouraged to implement the dual task exercises training as a routine practice for stroke patients to improve their balance, mobility, risk of falling and activities of daily living. Furthermore, dual task exercises should be included in conventional stroke rehabilitation program.

2. Replication of this study is recommended on several clinical settings for generalizability of the research results to other hospitals.

3. Conducting further study with paying attention to provide program sessions individually for patients to get excellency in program effect. 


\section{Effects of Dual Task Exercises Training Program on Stroke Patients}

\section{References}

Abd-Allah, F., Khedr, E., Oraby, M., \& Reda, R. (2019). Stroke burden in Egypt: Data from five epidemiological studies. Journal of the Neurological Sciences, 405, 9-10.

Aydoğdu, Y. T., Aydoğdu, O., \& İnal, H. S. (2018). The Effects of Dual-Task Training on Patient Outcomes of Institutionalized Elderly Having Chronic Stroke. Dementia and geriatric cognitive disorders extra, 8(3), 328-332.

Benjamin, E. J., Blaha, M. J., Chiuve, S. E., Cushman, M., Das, S. R., Deo, R., et al. (2017). Heart disease and stroke statistics-2017 update: a report from the American heart association. Circulation 135, e146-e603. doi: 10.1161/CIR.0000000000000485

Choi, J. H., Kim, B. R., Han, E. Y., \& Kim, S. M. (2015). The effect of dual-task training on balance and cognition in patients with subacute post-stroke. Annals of rehabilitation medicine, 39(1), 81.

Cortés-Pérez, I., Nieto-Escamez, F. A., \& Obrero-Gaitán, E. (2020). Immersive virtual reality in stroke patients as a new approach for reducing postural disabilities and falls risk: a case series. Brain sciences, 10(5), 296.

De Luca, A., Squeri, V., Barone, L. M., Vernetti Mansin, H., Ricci, S., Pisu, I., ... \& Sanfilippo, C. A. (2020). Dynamic Stability and Trunk Control Improvements Following Robotic Balance and Core Stability Training in Chronic Stroke Survivors: A Pilot Study. Frontiers in neurology, 11, 494.

de Sousa, D. G., Harvey, L. A., Dorsch, S., Varettas, B., Jamieson, S., Murphy,
A., \& Giaccari, S. (2019). Two weeks of intensive sit-to-stand training in addition to usual care improves sit-to-stand ability in people who are unable to stand up independently after stroke: a randomised trial. Journal of physiotherapy, 65(3), 152158.

Donkor, E. S. (2018). Stroke in the $21 \mathrm{st}$ century: A snapshot of the burden, epidemiology, and quality of life. Stroke research and treatment, 2018.

El-Hajj, M., Salameh, P., Rachidi, S., \& Hosseini, H. (2016). The epidemiology of stroke in the Middle East. European Stroke Journal, 1(3), 180-198.

Kal, E. C. (2018). Improving Movement Automaticity and Dual-Task Performance in People with Stroke: A Change of Focus?. Available at: http://dare.ubvu.vu.nl/bitstream/handle/187 1/55838/chapter\%204.pdf? sequence $=9$, accessed on Dec. 10, 2019.

Kim, J. H., \& Park, E. Y. (2014). Balance self-efficacy in relation to balance and activities of daily living in community residents with stroke. Disability and rehabilitation, 36(4), 295-299.

Kim, K. Y., Chun, S. P., Kang, T. G., \& Kim, G. D. (2015). Effects of core stability training on postural control ability and respiratory function in chronic stroke patients. Adv Sci Technol Lett, 88, 181186.

Kong, K. H., \& Lee, J. (2014). Temporal recovery of activities of daily living in the first year after ischemic stroke: a prospective study of patients admitted to a rehabilitation

unit. NeuroRehabilitation, 35(2), 221-226.

Landers, M. R., Oscar, S., Sasaoka, J., \& Vaughn, K. (2016). Balance confidence 
and fear of falling avoidance behavior are most predictive of falling in older adults: prospective analysis. Physical therapy, 96(4), 433-442.

Liu, Q., Wang, X., Wang, Y., Wang, C., Zhao, X., Liu, L., ... \& Wang, Y. (2018). Association between marriage and outcomes in patients with acute ischemic stroke. Journal of neurology, 265(4), 942948.

Meester, D., Al-Yahya, E., Dennis, A., Collett, J., Wade, D. T., Ovington, M.\& Dawes, H. (2019). A randomized controlled trial of a walking training with simultaneous cognitive demand (dual-task) in chronic stroke. European journal of neurology, 26(3), 435-441.

Pang, M. Y. C., Yang, L., Ouyang, H., Lam, F. M. H., Huang, M., \& Jehu, D. A. (2018). Dual-Task Exercise Reduces Cognitive-Motor Interference in Walking and Falls After Stroke: A Randomized Controlled Study. Stroke, 49(12), 29902998.

Park, J. (2019). Dual Task Training Effects on Upper Extremity Functions and Performance of Daily Activities of Chronic Stroke Patients. Osong public health and research perspectives, 10(1), 2.

Pollock, A., Baer, G., Campbell, P., Choo, P. L., Forster, A., Morris, J., \& Langhorne, P. (2014). Physical rehabilitation approaches for the recovery of function and mobility following stroke. Cochrane Database of Systematic Reviews, (4).

Rai, S. S., \& Ganvir, S. S. (2020). Effect of 2 Weeks of Dual Task Training on Balance and Gait in Patients with Stroke: Single Group Experimental
Study. International Journal of Health Sciences and Research, 10(2), 57-66.

Saunders, D. H., Greig, C. A., \& Mead, G. E. (2014). Physical activity and exercise after stroke: review of multiple meaningful benefits. Stroke, 45(12), 37423747.

Schinkel-Ivy, A., Inness, E. L., \& Mansfield, A. (2016). Relationships between fear of falling, balance confidence, and control of balance, gait, and reactive stepping in individuals with sub-acute stroke. Gait \& posture, 43, 154159.

Takeuchi, H., Magistro, D., Kotozaki, Y., Motoki, K., Nejad, K. K., Nouchi, R., ... \& Zecca, M. (2020). Effects of simultaneously performed dual-task training with aerobic exercise and working memory training on cognitive functions and neural systems in the elderly. Neural Plasticity, 2020.

Van de Steene, B. (2019). The effect of TDCS on motor function in chronic stroke patients (Doctoral dissertation, Ghent University).

Vos, T., Allen, C., Arora, M., Barber, R. M., Bhutta, Z. A., Brown, A., ... \& Coggeshall, M. (2016). Global, regional, and national incidence, prevalence, and years lived with disability for 310 diseases and injuries, 1990-2015: a systematic analysis for the Global Burden of Disease Study 2015. The Lancet, 388(10053), 1545-1602.

Xu, T., Clemson, L., O'Loughlin, K., Lannin, N. A., Dean, C., \& Koh, G. (2018). Risk factors for falls in community stroke survivors: a systematic review and meta-analysis. Archives of physical 


\section{$\underline{\text { Effects of Dual Task Exercises Training Program on Stroke Patients }}$}

medicine and rehabilitation, 99(3), 563573.

Yoon-Hee, C., Kyoung, K., Sang-Yong, L., \& Yong-Jun, C. (2020). Lower limb muscle activities and gain in balancing ability following two types of stair gait intervention in adult post-chronic stroke patients: A preliminary, randomizedcontrolled study. Turkish Journal of Physical Medicine and Rehabilitation, 66(1), 17.
Yu, K. H., \& Jeon, H. S. (2015). The effects of dual-task gait training on gait performance under cognitive tasks in chronic stroke. The Journal of Korean Physical Therapy, 27(5), 364-368.

Zhao, L. R., \& Willing, A. (2018). Enhancing endogenous capacity to repair a stroke-damaged brain: An evolving field for stroke research. Progres in neurobiology, 163, 5-26. 


\section{تأثير برنامج تدريبى للتمارين المزدوجة على مرضى السكتة الاماغية}

أسماء محمد محم عبدالحميد ـأميرة أحمد حننين على - حنان جابر كحم محمود -محم كمال حامد سنه ـإيمان صبحى عمران

تعتبر السكتة الدماغية السبب الرئيسى للإعاقة بين البالغين في جميع أنحاء العالم، فالهدف الأساسى من علاج مرضى السكتة الدماغية هو تأهيل المرضى لممارسة أنشطة الحياة اليومية. لذلك هدفت هذه الدر اسة إلى تقييم تأثير برنامج تدريبى للتمارين المزدوجة على مرضى السكتة الدماغية من حيث التوازن والحركة وخطر الوقوع. وقد أجريت الدر اسة في قسم المخ والأعصاب بمستشفى جامعة بنها على ع ـ ا مريض يعانى من السكتة الدماغية، حيث كثفت النتائج أن البرنامج التدريبى للتمارين المزدوجة له تأثير إيجابى على التوازن والحركة وخطر الوقوع فى مرضى السكتة الدماغية. كما أوصت الدراسة بضرورة تشجيع الممرضات على تطبيق التدريب بالتمارين المزدوجة لمرضى السكتة الدماغية لتحسين التوازن والحركة وخطر السقوط وممارسة أنشطة الحياة اليو مية. 